\title{
EFFECTS OF MUCOSAL HYPEROSMOLARITY ON ACTIVE SUGAR TRANSPORT AND THE SUGAR- EVOKED POTENTIAL IN ISOLATED SMALL INTESTINE OF THE TOAD
}

\author{
Yoshitaka SAITo and Takeshi HosHI \\ Department of Physiology, Tohoku University School of Medicine, Sendai, Japan
}

\begin{abstract}
Summary Isolated small intestines of toads were mounted in a flux chamber or suspended from a cannula as an everted sac, and osmolarity of solutions bathing the mucosal surface was changed by adding Dmannitol or polyethylene glycol to the standard solution. With increase in osmolarity we observed increases in (1) resistance of transmural water flow, (2) transmural electrical resistance, (3) tissue electrolyte content, (4) a decrease in water content of the tissue, (5) a change in transmural potential difference in the direction that the mucosal side becomes more positive, and (6) a reduction in size of the glucose-evoked potential. On the other hand the tissue uptake of D-glucose and Dgalactose from the mucosal solution did not significantly change with the treatment. Within a range of osmolarity change (less than $200 \mathrm{mOsm} /$ liter), results (3) and (4) can be interpreted as due to a mere withdrawal of water from the tissue. The relationship between the size of the osmotic potential change and the osmolarity difference was similar to that between the rate of net water flow and the osmolarity difference. The fact that mucosal hyperosmolarity exerts strong influence on the sugarevoked potential but no significant influence on the uptake of sugar is interpreted as the effect of the hyperosmolarity being a consequence of changes in electrical resistance representing the lateral intercellular space.
\end{abstract}

An elevation or a reduction of osmolarity of the solution bathing the mucosal surface of the small intestine is known to cause changes in passive permeability to water and organic solutes and in the transmural potential of the tissue. LoEsCHKE et al. $(1970,1971)$ have shown that osmotic water flow permeability and passive permeability to sugar molecules measured in the presence of phlorizin are distinctly higher in the presence of mucosal to serosal water flow than in the

Received for publication May 7, 1973

斎藤禎隆, 星 猛 
presence of water flow in the reverse direction. They ascribed such observed asymmetry to different structural changes which were induced concomitantly by osmotic gradients with different directions. SMYTH and Wright (1966) showed that the transmural potential difference of the small intestine was altered by changing osmolarity of the mucosal solution, and LoESCHKE et al. (1971) showed that the magnitude of such osmotic potential changes were also asymmetrical depending on the direction of elicited water flow. Similar asymmetrical permeability characteristics and the relation of them to structural changes in the epithelial cells induced by osmotic water flow have extensively been studied in the gall bladder (TORMEY and Diamond, 1967; Smulders et al., 1972; Wright et al., 1972).

The effect of transmural osmotic gradients on the active transport of nonelectrolytes by the small intestine has not been studied extensively. Parsons and Wingate (1961) found that changes in osmolarity of the mucosal solution by changing sodium concentration had little effect on glucose transport in rat small intestine. However, DiNDA et al. (1972) observed in hamster intestine a unique effect of the mucosal hyperosmolarity, which caused a marked depression of the movement of glucose from cell inside to the serosal fluid without affecting the mucosal entry of the sugar.

In the present study, the effect of the elevation of osmolarity of the mucosal solution on sugar transport and the sugar-evoked potential was investigated in isolated toad intestine. The sugar-evoked potential is known to be closely related to active sugar flux (LYON and CRANE, 1966; Hoshi and KOMATSU, 1968), but its relation to sugar flux or sugar-coupled $\mathrm{Na}^{+}$flux may be modified by changes in electrical properties of the intestinal tissue (Schultz et al., 1967). Since the reactions of the intestinal tissue to osmotic concentration gradients have not been well observed, changes in various passive properties of the intestinal tissue induced by the mucosal hyperosmolarity were first observed, and the observed changes in the transport function and the related electrical changes were discussed on the basis of findings on the osmotic reactions of the tissue.

\section{METHODS}

Preparations and incubation media. Toads (Bufo vulgaris) of either sex were used, and experiments were carried out throughout all seasons. The animal was anesthetized by an injection of a small amount $(0.2-0.3 \mathrm{ml})$ of $25 \%$ urethane solution into the cisterna magna. The upper small intestine, about $3-\mathrm{cm}$ long below the opening of the hepatopancreatic duct, was excised and rinsed in an isotonic mannitol $\left(\mathrm{Na}^{+}\right.$-free)-buffered solution. The segment of the intestine was used as an everted sac suspended from a polyethylene cannula or as a sheet mounted in a flux chamber depending on the purpose of experiments. The solution having the following composition was used as the standard medium; $\mathrm{Na}_{2} \mathrm{SO}_{4}$, $55 \mathrm{~mm}$; $\mathrm{KHCO}_{3}, 2.0 \mathrm{~mm} ; \mathrm{KH}_{2} \mathrm{PO}_{4}, 0.2 \mathrm{~mm} ; \mathrm{MgSO}_{4}, 1.0 \mathrm{~mm} ; \mathrm{CaSO}_{4}, 1.0 \mathrm{~mm}$; 
Tris- $\mathrm{SO}_{4}$ (pH 7.8), $5.0 \mathrm{~mm}$ and D-mannitol, $77 \mathrm{~mm}$. The reason for the use of the $\mathrm{SO}_{4}{ }^{--}$-Ringer solution was to maintain longer durability of the preparation and to obtain greater potential changes than in $\mathrm{Cl}^{-}$-Ringer. The osmolarity of the mucosal side was elevated by an addition of D-mannitol or polyethylene glycol (PEG, M.W. 400) at a desired concentration. It was seen that there was no significant difference in osmotic effects between these two substances, therefore, D-mannitol was used more frequently than PEG because of ease of handling.

Recording of the transmural potential difference. The everted sac suspended from a polyethylene tube was used. The potential difference between inside and outside the sac was recorded in the same way as previously described by HosHI and Komatsu (1968). The sac, filled with the standard solution, was immersed in the outside solution (the standard solution) of a relatively large volume $(20 \mathrm{ml})$. The outside solution was continuously bubbled with pure $\mathrm{O}_{2}$, and its temperature was kept at $25^{\circ} \mathrm{C}$. The osmolarity change in the mucosal solution caused little change in the liquid junction potential of the electrode, as reported by BARRY and DiAmond (1970).

Measurement of net water flow. A special type of the everted sac was used for this purpose. A small stainless wire mesh cylinder was attached to one end of a polyethylene tube, and the everted sac was fixed over the cylinder with slight distension. A glass capillary tube with the inner diameter of $2 \mathrm{~mm}$ was connected horizontally to the polyethylene tube. Net water flux was calculated from the meniscus movement of the serosal (inside) solution in the capillary tube. The horizontal capillary tube was fixed $2 \mathrm{~cm}$ above the surface of the mucosal solution. The hydrostatic pressure effect was negligibly small compared with the effect of the osmotic pressure gradient.

Measurements of changes in the tissue water and electrolyte content and in transmural electrical resistance. A sheet preparation and a lucite flux chamber were used for these measurements. An isolated segment of the intestine was opened along the mesenteric border, and a sheet of the tissue was mounted between the lucite half chambers. Each half chamber was separated by a septum into two parallel systems, each having an independent gas lift circulation system. On fixing the sheet, the tissue was separated into two symmetrical parts automatically. One of the parts was employed for control and the other was used for experimental conditions. Each chamber was initially filled with the standard solution. After $30 \mathrm{~min}$, the mucosal solution of one part was made hyperosmotic. After a time, the solutions of both sides were drained off and the preparation was removed immediately from the chamber. After the two parts were blotted on filter paper, they were cut free from each other, weighed on a torsion balance, then put into small test tubes of known weight. The dry weight of the tissue was determined after drying the sample overnight at $105^{\circ} \mathrm{C}$. The water content was determined from the difference in weight before and after drying.

Tissue electrolyte content was determined after extraction of electrolytes 
from either wet or dried samples with $1 \mathrm{ml}$ of either $5 \%$ trichloroacetic acid solution or deionized distilled water. The extraction tube containing the sample and the extraction fluid was heated in boiling water for several minutes, and allowed to stand overnight for equilibration. The tubes were reweighed, centrifuged for 20 min at $3,000 \mathrm{~g}$, then $\mathrm{Na}^{+}$and $\mathrm{K}^{+}$content of the supernatant was measured with a flame photometer (Erma).

The transmural electrical resistance was measured by passing constant (DC) current across the tissue. The current was supplied from an external battery through $\mathrm{Zn}-\mathrm{ZnSO}_{4}$ electrodes and bridges filled with $2 \%$ agar in the standard solution. The tips of the bridges were placed in the both solutions $3 \mathrm{~cm}$ apart from the gut wall. The transmural potential change due to applied current was recorded through $2 \%$ agar- $1 \mathrm{M} \mathrm{KCl}$ bridges, the tips of which were placed $3 \mathrm{~mm}$ apart from the surface of the tissue. The resistance was calculated from the potential drop and the applied current. Corrections were made for the fluid resistance between the recording electrodes.

Measurements of the mucosal entry of glucose and galactose. The tissue uptake of D-glucose and D-galactose during 10, 30, and 60 min incubation with these sugars was examined with sheet preparations in the absence or presence of an osmotic concentration difference. After preincubating the preparations for 30 min under the same osmotic conditions as in the uptake experiments, glucose plus ${ }^{14} \mathrm{C}$-glucose or galactose plus ${ }^{14} \mathrm{C}$-galactose was added to the mucosal solution to give the final concentrations of $10 \mathrm{~mm}$ and $0.25 \mu \mathrm{Ci} / \mathrm{ml}$. The treatment of the preparations after the end of the incubation were the same as those for the measurements of electrolyte content of wet tissues. The radioactivity of the extraction fluid was counted in a liquid scintillation counter (Aloka, model LSC 601 or Packard 3324).

All data presented in the figures and table were given as means \pm S.E.

\section{RESULTS}

\section{Reactions of tissue to the mucosal hyperosmolarity}

Net water movement. In the absence of osmotic concentration difference $(\Delta \mathrm{C})$, net water movement became nearly zero in about $30 \mathrm{~min}$ after setting-up. When the mucosal solution was made hyperosmotic, a significant water movement from the serosal to mucosal side was elicited. The rate of movement gradually increased with time to reach a steady value in about 50 or $60 \mathrm{~min}$. The rate estimated during the steady state was proportional to given $\Delta \mathrm{C}$, but the relation was found to be non-linear; the greater the $\Delta \mathrm{C}$, the smaller the rate per unit increase in $\Delta \mathrm{C}$ (Fig. 1). The values of the flow rate estimated at $\Delta \mathrm{C}$ of 100 and $200 \mathrm{mOsm} /$ liter were $16 \pm 2$ and $24 \pm 2 \mu \mathrm{l} \cdot \mathrm{cm}^{-2} \cdot \mathrm{hr}^{-1}(n=5)$, respectively.

The transmural potential difference. The transmural potential difference (PD) measured under isoosmotic conditions was slightly negative on the mucosal side 


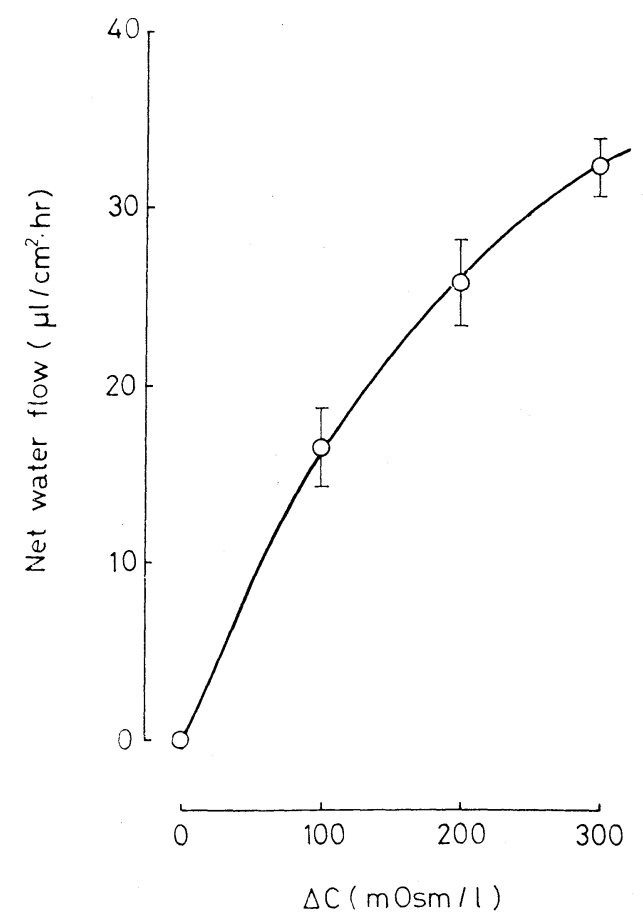

Fig. 1. Relationship between net water flow estimated at a steady state $(60 \mathrm{~min}$ after the elevation of the mucosal osmolarity) and applied osmotic concentration difference $(\Delta \mathrm{C})$.

with respect to the serosal side and stable for more than $2 \mathrm{hr}$. A marked change in the PD was produced when the mucosal side was made hyperosmotic. The PD change occurred in the direction that the mucosal side became more positive. The PD thus changed, reached a new steady level after 5 to $10 \mathrm{~min}$, the time course being much faster than that of equilibration of the water movement. After having reached the maximum, the level of the PD remained unchanged for more than $60 \mathrm{~min}$ when given $\Delta \mathrm{C}$ was less than $200 \mathrm{mOsm} / \mathrm{liter}$. With a greater $\Delta \mathrm{C}$, e.g., $300 \mathrm{mOsm} /$ liter, the $\mathrm{PD}$ declined spontaneously toward the isoelectric level after having reached the maximum. The size of the maximum potential shift was proportional to given $\Delta \mathrm{C}$, but the relation to $\Delta \mathrm{C}$ was also non-linear (Fig. 2). However, the size of the PD changes was found to be directly proportional to the rate of net water flow. The reproducibility of the PD change was well maintained when relatively small $\Delta \mathrm{C}$ was given repeatedly, but the reproducibility was frequently lost after an exposure to a high $\Delta \mathrm{C}$, e.g., $300 \mathrm{mOsm} / \mathrm{liter}$, or after a long exposure to $\Delta \mathrm{C}$ of $200 \mathrm{mOsm} /$ liter.

Water and electrolyte content of tissue. Significant changes in the tissue water and electrolyte content were induced by the mucosal hyperosmolarity. A 


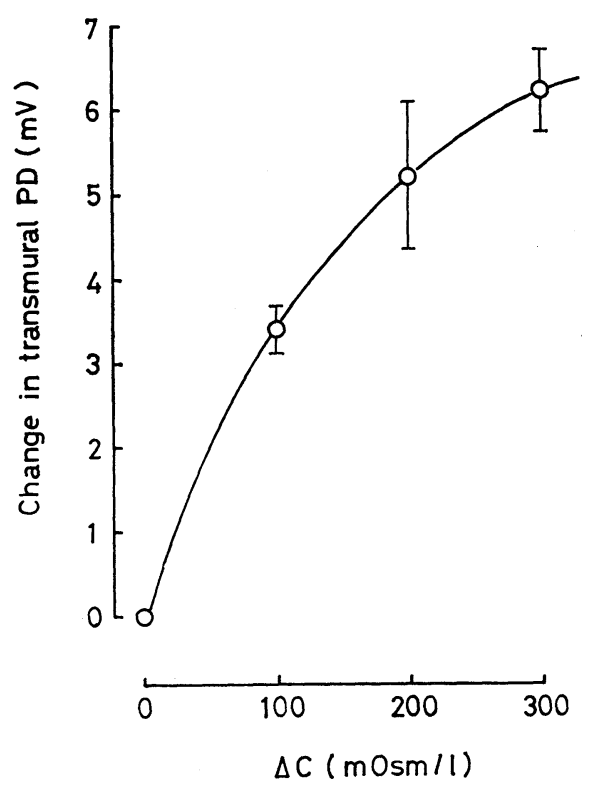

Fig. 2. Relation of the size of change in the transmural potential difference to applied $\Delta$ C. Number of preparations tested ranged from 6 to 8 except for $300 \mathrm{mOsm} /$ liter $(n=3)$.

steady state was achieved within about 30 min after the elevation of osmolarity. Figure 3 shows the relationships between the electrolyte and water content estimated after $60 \mathrm{~min}$ exposure and the magnitude of applied $\Delta \mathrm{C}$. Both $\mathrm{K}^{+}$and $\mathrm{Na}^{+}$linearly increased with increase in $\Delta \mathrm{C}$, while water content decreased linearly as $\Delta \mathrm{C}$ was increased. The linearity was held over the range of $\Delta \mathrm{C}$ from zero to $200 \mathrm{mOsm} /$ liter. Beyond this range, an abrupt deviation from the linear relation was found. The increases in $\mathrm{K}^{+}$and $\mathrm{Na}^{+}$content per unit osmolarity difference were 0.22 and $0.16 \mathrm{mEq} / \mathrm{kg}$ tissue $\mathrm{H}_{2} \mathrm{O}$, respectively. However, there was no difference between the values of the per cent increase for these two electrolytes with respect to the content in the absence of $\Delta \mathrm{C}$. The electrolyte content per unit dry weight remained unchanged after an exposure to $\Delta \mathrm{C}$ up to $200 \mathrm{mOsm} /$ liter. This indicates that the changes in the water and electrolyte content of the wet tissue are solely due to the withdrawal of water from the tissue. On the other hand, an exposure to $\Delta \mathrm{C}$ of $300 \mathrm{mOsm} /$ liter caused a significant decrease in the content per unit dry weight, indicating an occurrence of some damage to the tissue and consequently the leakage of electrolytes from the tissue.

Transmural electrical resistance. The control value of the resistance estimated in the standard solution was $142 \pm 27 \Omega \cdot \mathrm{cm}^{2}(n=4)$. When the mucosal osmolarity was elevated, the resistance began to increase immediately and tended to reach a new steady level. The greater the $\Delta \mathrm{C}$, the greater change was observed 

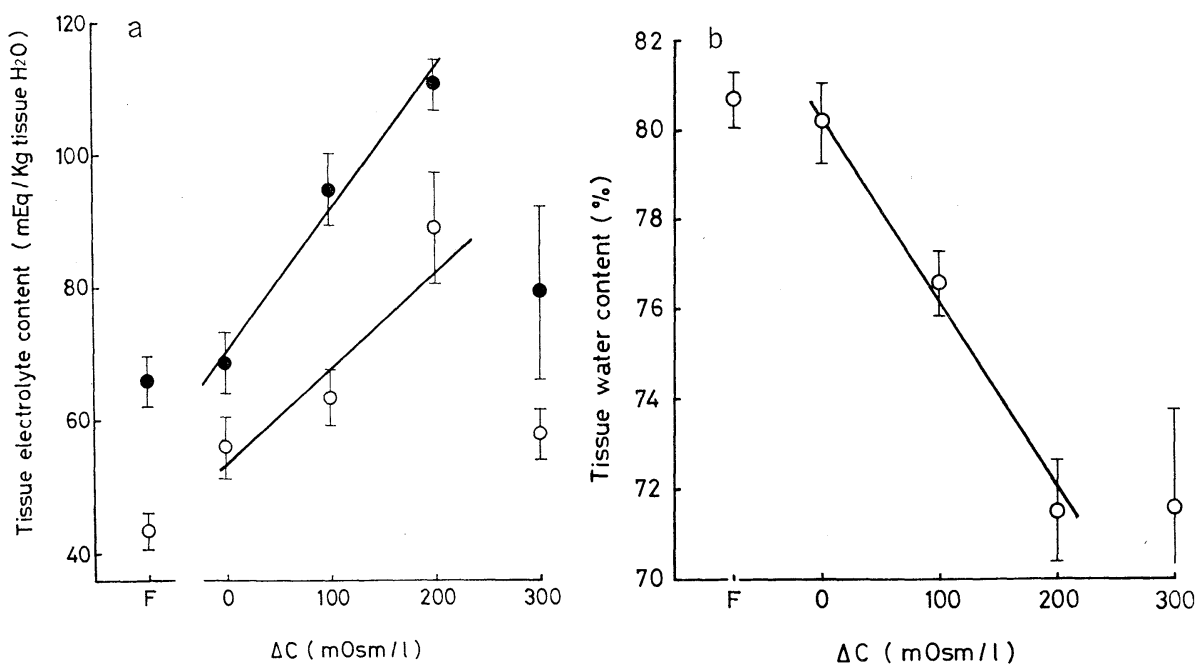

Fig. 3. The effect of the mucosal hyperosmolarity on the tissue electrolyte and water content. (a) The relationships between $\mathrm{K}^{+}$content and applied $\Delta \mathrm{C}$ (closed circle) and between $\mathrm{Na}^{+}$content and $\Delta \mathrm{C}$ (open circle). (b) The relationship between tissue water content and applied $\Delta \mathrm{C}$. $\mathrm{F}$ denotes fresh smaples. Number of preparations tested ranged from 4 to 14 .

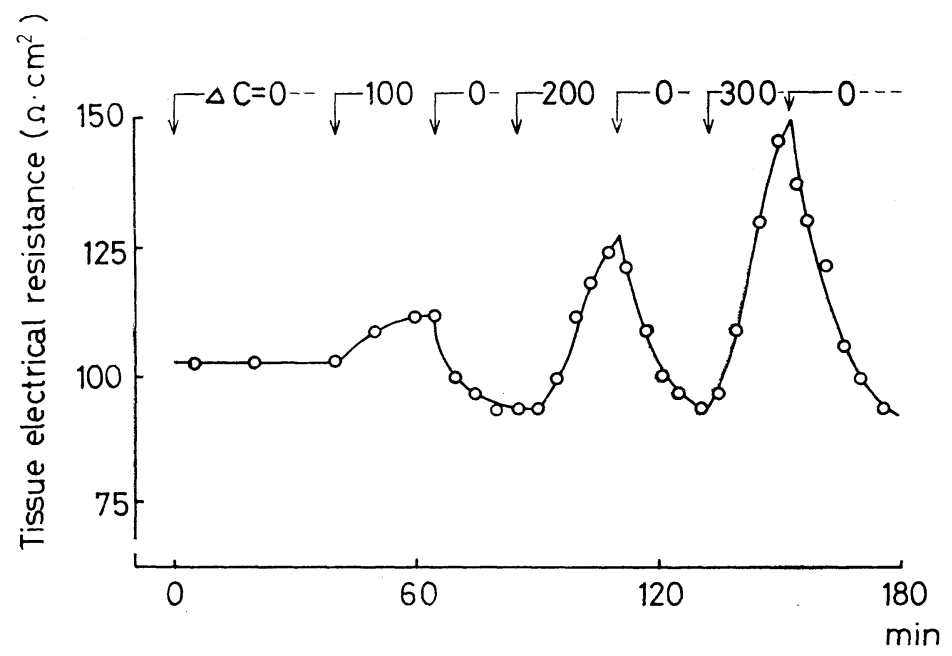

Fig. 4. Changes in the transmural electrical resistance of the small intestine caused by an elevation of the mucosal osmolarity. A sheet preparation was used. The osmolarity of the mucosal solution was elevated 100, 200, $300 \mathrm{mOsm} /$ liter higher than the isotonic level in succession. 
as shown in Fig. 4. These changes were found to be reversible.

When the epithelium was scraped off by use of a cover glass, the electrical resistance was reduced to about one-third or less the control value, and the effect of $\Delta \mathrm{C}$ was no more observed. A treatment of the mucosal surface with $30 \%$ formalin also eliminated the response to the mucosal hyperosmolarity. These indicate that most of the tissue resistance is localized at the epithelial cell layer and the resistance change above described occurs in this layer.

\section{Influence of the mucosal hyperosmolarity on the glucose-evoked potential and the mucosal entry of glucose}

Glucose-evoked potentials. The influence of the mucosal hyperosmolarity on the glucose-evoked potential was observed in the following way. The osmotic effect was monitored by recording the transmural PD change elicited by applied $\Delta \mathrm{C}$, and glucose was added to the mucosal solution when the osmotically induced potential change had reached a steady level. The final concentration of glucose added was $10 \mathrm{mM}$, which is known to give nearly the maximum sugar-evoked potentials in toads (Hoshi and KomATsu, 1968). Control recording was made twice, before and after recording in the presence of $\Delta \mathrm{C}$ (Fig. 5). The size of the glucoseevoked potential in the presence of $\Delta \mathrm{C}$ was expressed as per cent of the mean value of the two controls.

A definite inhibition was seen consistently. The per cent decrease of the height of the glucose-evoked potential was linearly proportional to applied

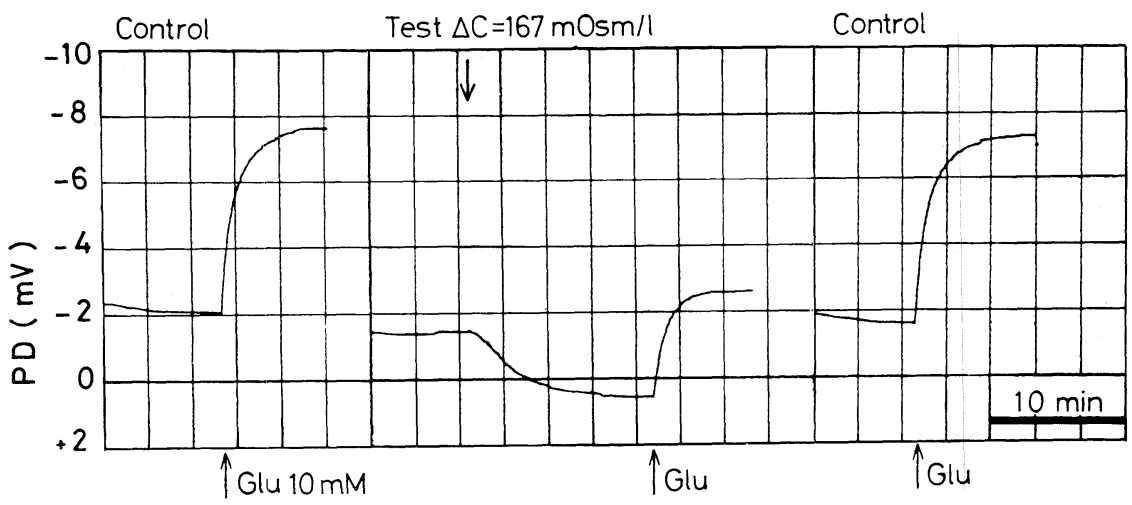

Fig. 5. An example of records of experiments where a comparison of the sugar-evoked potentials in the absence and presence of an osmotic concentration difference was made. A single preparation was used throughout this experiment. Before and after the test under the influence of $\Delta \mathrm{C}$ of $167 \mathrm{mOsm} / \mathrm{liter}$, control recording was made without osmotic gradient, and the mean value of the height of the two records was compared with that recorded under the influence of applied $\Delta \mathrm{C}$. The upward deflection of the tracing indicates an increase in the negativity of the mucosal side with respect to the serosal side. 
$\Delta \mathrm{C}$ (Fig. 6). Fifty per cent decrease was observed when $\Delta \mathrm{C}$ of $168 \mathrm{mOsm} /$ liter was applied. This inhibitory effect was nearly completely reversible, as far as the applied $\Delta \mathrm{C}$ did not exceed $200 \mathrm{mOsm} / \mathrm{liter}$. No other change was observed in the evoked potential, e.g., in the configuration of the potential.

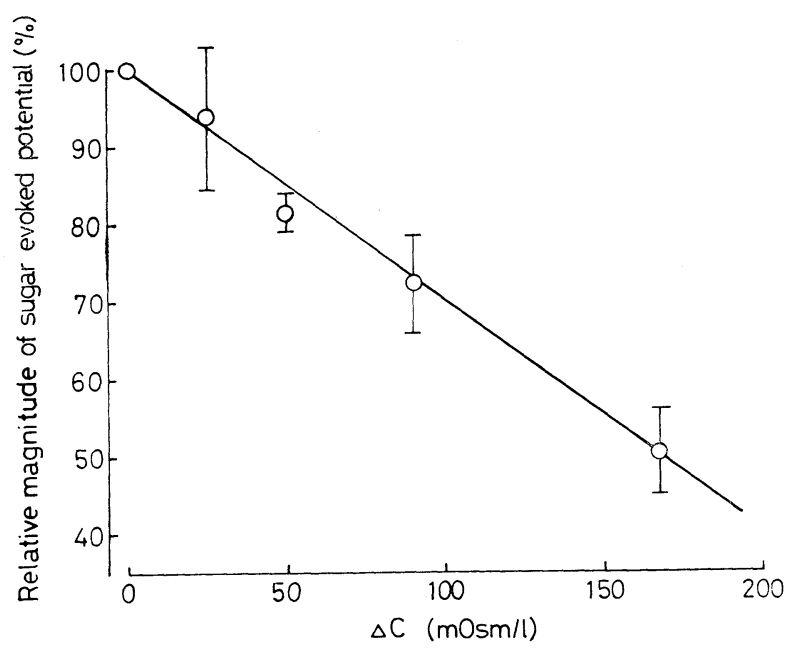

Fig. 6. Relative magnitude of the glucose-evoked potential recorded in the presence of various $\Delta \mathrm{C}$. The evoked potentials were produced by glucose added to the mucosal solution at $10 \mathrm{~mm}$. The mean value of two control records, as shown in Fig. 5, was made $100 \%$. Number of preparations ranged from 4 to 6 .

Table 1. Tissue uptake of D-glucose in the presence and the absence of osmolarity difference (mucosal hyperosmolarity).

The initial concentration of glucose in the incubation medium was $10 \mathrm{~mm}$. The amount of glucose uptake was expressed by tissue to medium concentration ratio $(\mathrm{T} / \mathrm{M})$.

\begin{tabular}{cccc}
\hline $\begin{array}{c}\text { Osmolarity } \\
\text { difference }(\Delta C) \\
\text { mOsm/liter }\end{array}$ & \multicolumn{3}{c}{$\mathrm{T} / \mathrm{M}$ ratio } \\
\cline { 2 - 4 } & $10 \mathrm{~min}$ & $30 \mathrm{~min}$ & $60 \mathrm{~min}$ \\
\hline 0 & $\begin{array}{c}0.37 \pm 0.07 \\
(n=5)\end{array}$ & $\begin{array}{c}0.65 \pm 0.09 \\
(n=4)\end{array}$ & $\begin{array}{c}0.95 \pm 0.33 \\
(n=3)\end{array}$ \\
\hline 100 & $\begin{array}{c}0.42 \pm 0.07 \\
(n=5)\end{array}$ & $\begin{array}{c}0.73 \pm 0.19 \\
(n=4)\end{array}$ & $\begin{array}{c}1.70 \pm 0.68 \\
(n=3)\end{array}$ \\
\hline 0 & $\begin{array}{c}0.34 \pm 0.12 \\
(n=5)\end{array}$ & $\begin{array}{c}0.93 \pm 0.17 \\
(n=4)\end{array}$ & $\begin{array}{c}1.56 \pm 0.47 \\
(n=4)\end{array}$ \\
200 & $0.36 \pm 0.12$ & $1.08 \pm 0.22$ & $1.83 \pm 0.56$ \\
$(n=5)$ & $(n=4)$ & $(n=4)$ \\
\hline
\end{tabular}


Mucosal entry of sugars. The tissue uptake of D-glucose from the mucosal solution during three different incubation periods, 10, 30, and $60 \mathrm{~min}$, was compared in the absence and presence of $\Delta \mathrm{C}$ of 100 and $200 \mathrm{mOsm} / \mathrm{liter}$. The concentration of glucose in the mucosal solution was fixed at $10 \mathrm{~mm}$ in order to equalize the conditions to those under which the influence on the evoked potentials was investigated. The data were summarized in Table 1. The mucosal hyperosmolarity appeared to cause a slight increase in the rate of uptake as compared to control, but the differences were statistically insignificant. D-galactose was also tested in the same way, but there was no difference in results from those on D-glucose.

\section{DISCUSSION}

An elevation of osmolarity of the solution bathing the mucosal surface of the small intestine produced not only net water flow from serosal to mucosal side but also changes in tissue water and electrolyte content and some electrical properties of the tissue. These changes were found to be reversible when applied $\Delta \mathrm{C}$ did not exceed $200 \mathrm{mOsm} /$ liter. A higher $\Delta \mathrm{C}$ frequently caused a loss of reproducibility of the osmotic potential changes and a marked decrease in the electrolyte content per unit dry weight. KAMEDA et al. (1968) showed histologically that an exposure of the intestinal mucosa to a hypertonic solution, e.g., a solution $550 \mathrm{mOsm} /$ liter higher than the isotonic, caused some damage of tissue, such as the necrosis of the epithelial cells or the increased exfoliation of the epithelium at the tip of the villi. LOESCHKE et al. (1971) also showed that a prolonged exposure to a solution of a moderate hypertonicity caused the similar histological changes.

All the reversible changes found in the present study can be regarded as the results of induced net water flow and the withdrawal of water alone from the tissue. Net water flow estimated under the conditions of $\Delta \mathrm{C}$ of 100 and $200 \mathrm{mOsm} /$ liter were 16 and $24 \mu \mathrm{l} \cdot \mathrm{cm}^{-2} \cdot \mathrm{hr}^{-1}$, respectively. The values are similar to those for the flow in the same direction obtained in frog intestine by LOESCHKE et al. (1971). They pointed out that the value for serosal to mucosal flow is much smaller than, about one sixth, that for the flow in the inverse direction. Furthermore, our results show that the rate of serosal to mucosal water flow per unit increase in $\Delta \mathrm{C}$ decreases as $\Delta \mathrm{C}$ is increased. This indicates that the resistance of tissue to water flow increases as $\Delta \mathrm{C}$ is increased. A similar increase in the flow resistance was seen also in the gall bladder by DiAmond (1966), SMULDERs et al. (1972) and Wright et al. (1972) when the mucosal solution was made hypertonic. They clearly demonstrated that such an increase in the flow resistance was associated with the shrinkage of the villus core and the collapse of the lateral intercellular space. LOESCHKE et al. (1971) also demonstrated in frog intestine that serosal to mucosal osmotic water flow caused the closure of the intercellular space.

It is of interest in conjunction with the increase in the flow resistance that the transmural electrical resistance is increased by the mucosal hyperosmolarity and 
the increase is dependent on the magnitude of applied $\Delta C$. In the gall bladder, the similar increase in the electrical resistance is produced by the mucosal hyperosmolarity in parallel with the increase in the flow resistance. Such an increase in the electrical resistance has never been seen in other tissues, e.g., frog skin (Ussing, 1965 ) and the renal tubule (WINDHAGER et al., 1966). Accordingly, the increase in both electrical and flow resistances can be regarded as phenomena specific to epithelial tissues having the villus structure and the lateral intercellular space which is believed to be an important path for water and solutes in isotonic fluid absorption as suggested by DiAmond and BosSERT (1967) and TORMEY and DiAmOND (1967).

In the range of $\Delta \mathrm{C}$, which caused reversible changes, per cent increase in $\mathrm{K}^{+}$ and $\mathrm{Na}^{+}$content were about the same, and the content of these electrolytes per unit dry weight remained unchanged after an exposure to a hyperosmolarity for about $60 \mathrm{~min}$. These findings suggest that only water is extracted from the tissue during an exposure to the hyperosmolarity. As $\mathrm{K}^{+}$is largely confined to the intracellular fluid while $\mathrm{Na}^{+}$to the extracellular fluid, the findings also suggest that there exists a considerable unstirred space within the tissue. Probably, the lateral intercellular space and at least a part of the villus core would be unstirred under the conditions of in vitro experiments as used in the present study.

The transmural PD was altered by changing mucosal osmolarity as first observed by SMYTH and Wright (1966). They proposed that the PD change was a kind of the electrokinetic phenomena, the streaming potential. Subsequently, WEDNER and DIAMOND (1969) suggested that the osmotic PD changes in the gall bladder were mostly boundary diffusion potential due to changes in salt concentrations in unstirred layers within the tissue. The polarization effect of osmotic water flow has been further analyzed by WRIGHT et al. (1972) and they strengthened this view. On the other hand, FröMTER and DiAMOND (1972) clearly demonstrated in the gall bladder that the main route of passive ion movement was the region of the tight junction. As to the small intestine, Frizzell and Schultz (1972) showed that about $85 \%$ of overall ionic conductance of tissue was shared by the conductance of the extracellular shunt pathway in rabbit ileum. In both the small intestine and gall bladder, such the extracellular shunt path has much higher permeability to monovalent cations than to anions (WrighT and DIAMOND, 1968; Frizzell and Schultz, 1972). From these studies, it is likely that most osmotic potential changes are produced across the tight junction, the outermost region of the epithelium.

It must be pointed out that the time course of the osmotic PD change is quite similar to that of the sugar-evoked potential. As sugar molecules transferred into cells or to the lateral space may create osmotic water flow across the mucosal membrane and/or the tight junction, a question may arise that the sugar-evoked potential might be of the same nature as that of the osmotic potential changes. However, $\Delta \mathrm{C}$ of $100 \mathrm{mOsm} /$ liter causes potential changes of only a few millivolts, while $10 \mathrm{~mm}$ glucose added to the mucosal solution produces much greater PD 
changes immediately without showing a transient decrease in the mucosal negativity. This suggests that the mechanism of the genesis of the sugar-evoked potential is entirely different from that of the osmotic potential change and the participation of the osmotic potential is negligibly small in the formation of the sugarevoked potential. As to the site of generation of the sugar-evoked potentials, Hoshi and Komatsu (1970), Rose and Schultz (1971) and White and Armstrong (1971) demonstrated evidence showing that the site is the brush border membrane of cells, while Gilles-Baillien and Schoffeniels (1965), Wright (1966), Lyon and Sheerin (1971) and BARry and EgGenton (1972) proposed that an electrogenic sodium pump located at the serosal membrane might be stimulated by increased sodium entry coupled with sugar molecules. Thus, there are still controversial views on this problem, but all investigators think the mucosal or serosal membrane of cells as the site of generation.

The mucosal entry of glucose and galactose was not affected significantly or slightly increased by the mucosal hyperosmolarity. This finding is essentially in accord with that of DINDA et al. (1972). They, however, showed that the transfer of sugar from cells to the serosal fluid was markedly depressed by the mucosal hyperosmolarity. They interpreted this depression as the consequence of water flow in the inverse direction to that of solute flow, thus the diminution of sweeping effect of water movement in the lateral space. In addition to such a mechanism, it would also be possible that the collapse of the lateral intercellular space under the influence of the mucosal hyperosmolarity may cause a diminution of diffusion area to sugar molecules at the lateral face of cells. PARsons and Wingate (1961), on the other hand, observed no effect of the mucosal hypo- and hyperosmolarity on glucose transport by rat small intestine. However, they elevated or decreased sodium concentration in order to change the osmolarity of the mucosal solution. As demonstrated by TORMEY and DiAMOND (1967), the width of the lateral intercellular space measured by electronmicroscopic observations is in parallel with the rate of sodium transport measured in parallel experiments. Therefore, it is probable that the observations by PARsons and Wingate on the effect of the mucosal hyperosmolarity were made under conditions of an increased sodium transport, hence in the absence of the collapse of the lateral space.

In contrast to unchanged mucosal transfer of sugars, the sugar-evoked potentials were markedly depressed by the mucosal hyperosmolarity and the extent of the depression was directly proportional to applied $\Delta \mathrm{C}$. The configuration of the evoked potentials, however, was not altered. It is known that anoxia, various metabolic inhibitors, and ouabain, all modify the sugar transport or its driving force, cause a significant alteration of the configuration, especially the loss of the formation of the plateau (Hoshi and Komatsu, 1970). Therefore, the observed diminution of the size without alteration of the configuration can be interpreted as the consequence of alteration in passive electrical properties of the epithelium rather than the changes in the transport machinary or the driving force. 
The active transport of hexoses by the small intestine is electrogenic in the sence that it causes an increment of the transmural PD (BARRY et al., 1963; LYON and Crane, 1966; Hoshi and Komatsu, 1968) and an increase in the shortcircuit current (Schultz and ZALusky, 1964; Schultz et al., 1967). In the case where only the transmural or transepithelial PD change is concerned, a simple electrical model, essentially the same as that applied to many ion transporting epithelia, e.g., the frog skin (Ussing and ZERAHN, 1951) can be applied to the small intestine. Furthermore, when only the sugar-evoked increments in the PD and short-circuit current are concerned, it would be enough to consider only an electromotive force (EMF) which creates sugar-coupled increases in $\mathrm{Na}^{+}$current. Such a model is illustrated in Fig. 7 by heavy lines. Ri represents the internal

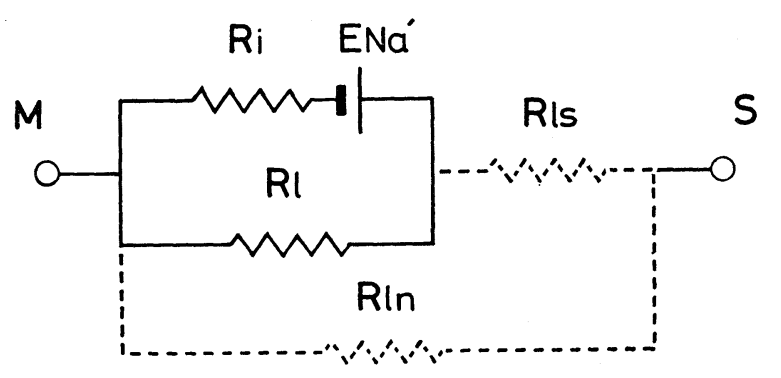

Fig. 7. Equivalent electrical circuit of the intestinal wall for the explanation of sugar transport-dependent changes in the transmural potential difference under the influence of the mucosal hyperosmolarity. The part of the circuit drawn with heavy lines indicates electrical components of the epithelial cell layer having a sugar-dependent electromotive force $\left(E_{N a}^{\prime}\right)$. $\mathrm{Ri}$ and $\mathrm{R} 1$ represent the internal resistance of $\mathrm{E}_{\mathrm{Na}}^{\prime}$ and the leak resistance across the cell layer (mostly the resistance of the tight junction) respectively. The additional circuit drawn with dotted lines including Rls and RIn is assumed to be latent under the normal conditions but to become apparent under the influence of serosal to mucosal osmotic water flow. Rls represents the resistance across the lateral intercellular space and Rln the leak resistance through non-transporting cells. $\mathrm{M}$ and $\mathrm{S}$ denote the mucosal and serosal fluids, respectively.

resistance of this EMF $\left(E_{\mathrm{Na}}^{\prime}\right)$ and $\mathrm{R} 1$ is the shunt resistance of the $\mathrm{EMF}$, which is assumed to be mainly determined by the resistance across the tight junction. Under normal conditions or in the presence of mucosal to serosal flow of water, this model seems to be sufficient to explain the sugar-evoked changes in electrical properties of the intestine. In the present case, it is reasonable to assume that the EMF created by active sugar transport mechanism remains unchanged during exposure to mucosal hyperosmolarity, because (1) sugar flux across the mucosal border remained almost unchanged, (2) the configuration of the evoked potential is normal, and (3) the sugar-induced increment of the short-circuit current is accounted for by 1: 1 coupling between sugar molecules and sodium ions (SCHULTZ and ZALUSKY, 1964; GoldNER et al., 1969), regardless of the ionic composition 
of the medium. If the model above described is used and the assumption is accepted, the diminution of the amplitude could be ascribed to a decrease in the shunt resistance, R1. However, this contradicts with the observed increase in the transmural electrical resistance. From the facts that both the flow resistance and the electrical resistance are increased by the mucosal hyperosmolarity and that these changes are known to be correlated with the ultrastructural changes in the epithelium, we must consider additional resistance components as shown by dotted lines in Fig. 7. One is the resistance of the lateral intercellular space (Rls) and the other (Rln) is the sum of leak resistances of the non-transporting cells, such as goblet cells and immature cells at the region of the Lieberkühn's crypts. When Rls is increased by the mucosal hyperosmolarity, both the diminution of the size of the sugar-evoked potential and an increase in the transmural resistance are simultaneously explained. Alternatively, both Rls and Rln are increased but the increase of Rls is larger than that of Rln. Although such resistance components have not been considered in the equivalent electric circuit for the intestinal epithelium reported thus far (Rose and Schultz, 1971; White and Armstrong, 1971), the present study suggests usefulness of considering these components for the explanation of electrical behaviour of the intestinal tissue under the influence of osmotic water flow from the serosal to mucosal side or under other conditions causing the collapse of the lateral space. Whether the same thing also occurs in the intestine normally perfused with blood is not known. However, it is possible that such an asymmetry in flow resistance and ionic conductance has some physiological meanings, e.g., in preventing fluid movement from blood to the lumen of the intestine when hypertonic luminal content is present.

\section{REFERENCES}

BARRY, P. H. and DiAmond, J. M. (1970) Junction potentials, electrode standard potential and other problems in interpreting electrical properties of membranes. J. Membrane Biol., 2: 93-122.

Barry, R. J. C., Dikstein, S., Matthews, J., Smyth, D. H., and Wright, E. M. (1963) Electrical potentials associated with intestinal sugar transfer. J. Physiol., 171, 316-338.

BARRY, R. J. C. and EgGenton, J. (1972) Membrane potentials of epithelial cells in rat small intestine. J. Physiol., 277: 201-216.

Diamond, J. M. (1966) Non-linear osmosis. J. Physiol., 183: 58-82.

Diamond, J. M. and Bossert, W. H. (1967) Standing-gradient osmotic flow. J. Gen. Physiol., 50: 2061-2083.

Dinda, P. K., Beck, M., and Beck, I. T. (1972) Effect of changes in the osmolarity of the luminal fluid on water and glucose transport across hamster jejunum. Can. J. Physiol. Pharmacol., 50: 83-86.

Frizzell, R. A. and Schultz, S. G. (1972) Ionic conductances of extracellular shunt pathway in rabbit ileum. Influence of shunt on transmural sodium transport and electrical potential differences. J. Gen. Physiol., 59: 318-346.

Frömter, E. and DiAmond, J. M. (1972) Route of passive ion permeation in epithelia. Nature (New Biology), 235: 9-13. 
Gilles-BAillien, M. and Schoffeniels, E. (1965) Site of action of L-alanine and D-glucose on the potential difference across the intestine. Arch. Int. Physiol. Biochim., 73: 355357.

Goldner, A. M., Schultz, S. G., and Curran, P. F. (1969) Sodium and sugar fluxes across the mucosal border of rabbit ileum. J. Gen. Physiol., 53: 362-383.

Hoshi, T. and Komatsu, Y. (1968) Sugar-evoked potential in isolated toad intestine. Jap. J. Physiol., 18: 508-519.

Hoshi, T. and Komatsu, Y. (1970) Effects of anoxia and metabolic inhibitors on the sugarevoked potential and demonstration of sugar-outflow potential in toad intestine. Tohoku J. Exp. Med., 100: 47-59.

Kameda, H., Abei, T., Nasrallah, S., and Iver, E. L. (1968) Functional and histological injury to intestinal mucosa produced by hyperosmolarity. Am. J. Physiol., 214: 1090-1095.

Loeschke, K., Bentzel, C. J., and Csaky, T. Z. (1970) Asymmetry of osmotic flow in frog intestine: functional and structural correlation. Am. J. Physiol., 218: 1723-1731.

Loeschke, K., Hare, D., and Csaky, T.Z. (1971) Passive sugar flux across frog jejunum in vitro. Pflügers Arch., 328: 1-20.

LyON, I. and CRANE, R. K. (1966) Studies on transmural potentials in vitro in relation to intestinal absorption. 1. Apparent Michaelis constants for $\mathrm{Na}^{+}$dependent sugar transport. Biochim. Biophys. Acta, 112: 278-291.

Lyon, I. and Sheerin, H. E. (1971) Studies on transmural potentials in vitro in relation to intestinal absorption. Vl. The effect of sugars on electrical potential profiles in jejunum and ileum. Biochim. Biophys. Acta, 249: 1-14.

Parsons, D. S. and Wingate, D. L. (1961) The effect of osmotic gradients on fluid transfer across rat intestine in vitro. Biochim. Biophys. Acta, 46: 170-183.

Rose, R. C. and Schultz, S. G. (1971) Studies on the electrical potential profile across rabbit ileum. Effects of sugars and amino acids on transmural and transmucosal electrical potential differences. J. Gen. Physiol., 57: 639-663.

Schultz, S. G., Curran, P. F., and Wright, E. M. (1967) Interpretation of hexose-dependent electrical potential differences in small intestine. Nature, 214: 509-510.

Schultz, S. G. and Zalusky, R. (1964) Ion transport in isolated rabbit ileum. II. The interaction between active sodium and active sugar transport. J. Gen. Physiol., 47: 1043-1059.

Smulders, A. P., Tormey, J. McD., and Wright, E. M. (1972) The effect of osmotically induced water flow on the permeability and ultrastructure of rabbit gallbladder. J. Membrane Biol., 7 : 164-197.

Smyth, D. H. and Wright, E. M. (1966) Streaming potentials in the rat small intestine. $J$. Physiol., 182: 591-602.

Tormey, J. MCD. and Diamond, J. M. (1967) The ultrastructural route of fluid transport in rabbit gall-bladder. J. Gen. Physiol., 50: 2031-2060.

Ussing, H. H. (1965) Relationship between osmotic reactions and active sodium transport in the frog skin epithelium. Acta Physiol. Scand., 63: 141-155.

Ussing, H. H. and ZERAHN, K. (1951) Active transport of sodium as the source of electric current in the short-circuited isolated frog skin. Acta Physiol. Scand., 23: 110-127.

Wedner, H. J. and Diamond, J. M. (1969) Contributions of unstirred-layer effects to apparent electrokinetic phenomena in the gallbladder. J. Membrane Biol., 1: 92-108.

White, J. F. and Armstrong, W. MCD. (1971) Effect of transported solutes on membrane potentials in bullfrog small intestine. Am. J. Physiol., 221: 194-201.

Windhager, E. E., Boulpaep, E. L., and Giebisch, G. (1966) Electrophysiological studies on single nephrons. Proc. 3rd Int. Congr. Nephrol., Washington, Vol. 1, pp. 35-47.

Wright, E. M. (1966) The origin of the glucose dependent increase in the potential difference across the tortoise small intestine. J. Physiol., 185: 486-500. 
Wright, E. M. and Diamond, J. M. (1968) Effect of pH and polyvalent cations on the selective permeability of gall-bladder epithelium to monovalent ions. Biochim. Biophys. Acta, 163: $57-74$.

Wright, E. M., SMulders, A. P., and TormeY, J. MCD. (1972) The role of the lateral intercellular spaces and solute polarization effects in the passive flow of water across the rabbit gallbladder. J. Membrane Biol., 7: 198-219. 